\title{
Leading cancers contributing to educational disparities in cancer mortality in the US, 2017
}

\author{
Diana R. Withrow ${ }^{1}\left[\right.$ - Neal D. Freedman ${ }^{1} \cdot$ James T. Gibson $^{2} \cdot$ Mandi Yu $^{3} \cdot$ Anna M. Nápoles $^{4} \cdot$ \\ Amy Berrington de González ${ }^{1} \cdot$ Meredith S. Shiels ${ }^{1}$
}

Received: 9 November 2020 / Accepted: 22 June 2021 / Published online: 9 July 2021

(c) The Author(s) 2021

\begin{abstract}
Purpose To inform prevention efforts, we sought to determine which cancer types contribute the most to cancer mortality disparities by individual-level education using national death certificate data for 2017.

Methods Information on all US deaths occurring in 2017 among 25-84-year-olds was ascertained from national death certificate data, which include cause of death and educational attainment. Education was classified as high school or less ( $\leq 12$ years), some college or diploma (13-15 years), and Bachelor's degree or higher ( $\geq 16$ years). Cancer mortality rate differences (RD) were calculated by subtracting age-adjusted mortality rates (AMR) among those with $\geq 16$ years of education from AMR among those with $\leq 12$ years.

Results The cancer mortality rate difference between those with a Bachelor's degree or more vs. high school or less education was 72 deaths per 100,000 person-years. Lung cancer deaths account for over half (53\%) of the RD for cancer mortality by education in the US.

Conclusion Efforts to reduce smoking, particularly among persons with less education, would contribute substantially to reducing educational disparities in lung cancer and overall cancer mortality.
\end{abstract}

Keywords Cancer mortality $\cdot$ Disparities $\cdot$ Lung cancer $\cdot$ Risk difference $\cdot$ Education

\section{Abbreviations \\ $A M R \quad$ Age-adjusted mortality rate \\ $R D \quad$ Rate difference}

Within the United States, disparities in cancer mortality rates by socio-economic status are large and have increased over recent years [1]. To inform prevention efforts, we examined differences in mortality rates from the 15 leading

Diana R. Withrow

diana.withrow@nih.gov

1 Division of Cancer Epidemiology \& Genetics, National Cancer Institute, National Institutes of Health, Rockville, MD, USA

2 Information Management Services Inc, MD, USA

3 Surveillance Research Program, Division of Cancer Control \& Population Sciences, National Cancer Institute, National Institutes of Health, Rockville, MD, USA

4 Division of Intramural Research, National Institute for Minority Health and Disparities, National Institutes of Health, Bethesda, MD, USA causes of cancer death by educational level and examined how disparities for each cancer contributed to the disparity observed overall.

Information on all US deaths occurring in 2017 among 25-84-year-olds was ascertained from national death certificate data, which include cause of death and educational attainment [2]. Education was classified as high school or less ( $\leq 12$ years), some college or diploma (13-15 years), and Bachelor's degree or higher ( $\geq 16$ years). Cancer deaths were classified based on ICD-10 codes.

Population denominators were linearly extrapolated from the American Community Survey (ACS) $1 \%$ Integrated Public Use Microdata for 2006-2014, stratified by education, age, sex and race/ethnicity. Extrapolation was used because this was the most recent ACS data available at the time of preparation of the dataset. Cancer mortality rate differences (RD) were calculated by subtracting age-adjusted mortality rates (AMR) among those with $\geq 16$ years of education from AMR among those with $\leq 12$ years.

Cancer mortality rates in 2017 were $47 \%$ higher among persons with $\leq 12$ years of education (AMR: 224.7/100,000 person-years, Supplementary Fig. 1) than among people 
with $\geq 16$ years (AMR: 152.6; RD:72.3/100,000, Fig. 1), with larger differences observed among men (RD: 117.5) than women (RD: 45.2).

By site, lung cancer was the largest contributor to the overall RD in both men and women, accounting for half of the difference $\left(\mathrm{RD}_{\text {male }}: 54.9, \mathrm{RD}_{\text {female }}: 27.5\right.$, Fig. 1). Among men, the next leading contributors were liver (RD: 10.5), colorectal (RD: 10.2) and esophageal cancers (RD: 5.1) Among women, the next leading contributors were colorectal (RD: 4.0), liver (RD: 2.2) and stomach cancers (RD: 1.2). Although breast and prostate cancers are the second and third leading causes of cancer mortality in women and men respectively, the RDs by educational level for these cancers were small $\left(\mathrm{RD}_{\text {breast: }}\right.$ - $\left.0.7, \mathrm{RD}_{\text {prostate: }}: 3.9\right)$.

Cancer mortality RDs by educational attainment were higher for non-Hispanic white (RD: 89.9) and non-Hispanic black adults (RD: 74.7) than among Asian/Pacific Islander (RD: 6.2) and Hispanic adults (RD: 4.9). Exploratory analyses suggested that the RDs among Asian/Pacific Islander and Hispanic adults were driven by differences in mortality rates by education among men, more so than among non-Hispanic white and black adults, where patterns were similar by sex (not shown).

Lung cancer deaths account for over half (53\%) of the $\mathrm{RD}$ for cancer mortality by education in the US. Cigarette smoking causes most lung cancers and profound educational disparities in smoking have been noted in the US [3]. National Health Interview Survey 2017 data indicate that $5.9 \%$ of people with a Bachelor's degree or more smoke vs. $24.9 \%$ of people with less than a high school education [4]. Lung cancer was the largest contributor to disparities in all racial/ethnic groups, except for Hispanic adults, likely due to smaller education-related disparities in smoking behavior within Hispanic populations than white populations [5, 6]. Smoking is a risk factor for 7 of 15 leading causes of cancer death, thus, eliminating disparities in cigarette smoking would do much to eliminate educational disparities in US cancer mortality rates.

Strengths of our analysis include use of data on all deaths occurring in the country and stratification of mortality rates by sex, race/ethnicity, and education. Because of the large population size, any error imposed by sampling variation in estimating the populations using the ACS was negligible [7]. The primary limitation of this work is that education may be misreported on death certificates, and this may be differential by race/ethnicity and age. In the past, Black and Hispanic high school graduates and older decedents were most likely to have their education under-reported [8, 9]. Additionally, while all other states used the 2003 revised US Standard Death Certificate which assessed highest degree completed, West Virginia transitioned from the 1999 version, assessing years of education, to the 2003 version over the course of 2017 [10]. By aggregating persons with high school and less education, we minimized the impact of these potential misclassifications.

Our results underscore that educational disparities in smoking contribute substantially to disparities in lung cancer and overall cancer mortality. Reductions in smoking prevalence would also reduce deaths from many smokingassociated diseases and cancer types, saving millions of lives annually $[11,12]$. 


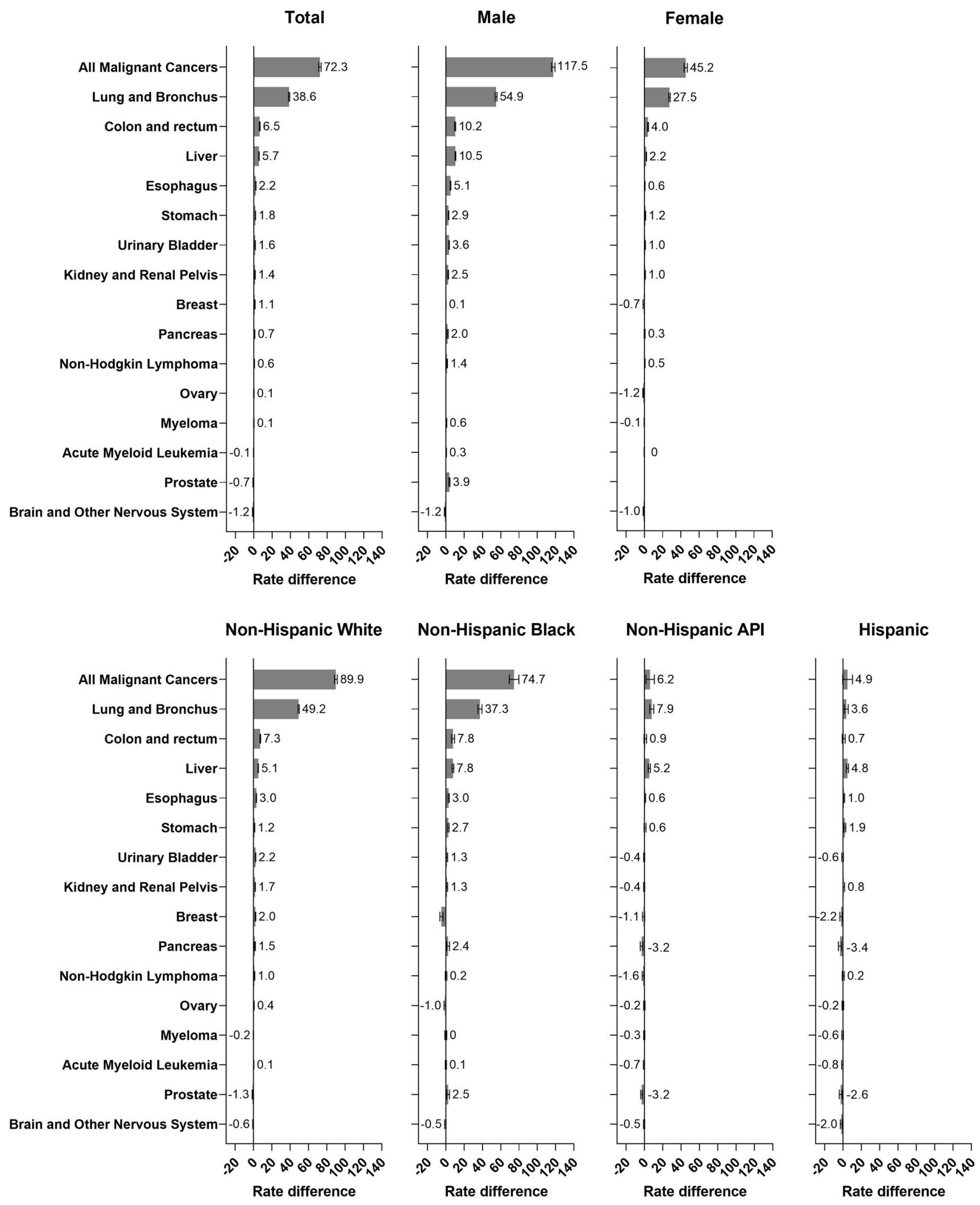

Fig. 1 Cancer mortality rate differences, $\geq 16$ years vs. $\leq 12$ years of education, stratified by sex and race/ethnicity; all 2017 deaths among persons aged 25-84 in the US; rate differences are age-standardized to the 2000 US standard population and are expressed per 100,000 person-years and 95\% confidence intervals are displayed; API: Asian and Pacific Islander 
Supplementary Information The online version contains supplementary material available at https://doi.org/10.1007/s10552-021-01471-9.

Authors' contributions All authors contributed to the study conception and design. Material preparation, data collection and analysis were performed by Meredith Shiels, Neal Freedman, and Diana Withrow. The first draft of the manuscript was written by Diana Withrow and all authors commented on subsequent versions of the manuscript. All authors read and approved the final manuscript.

Funding This work was supported by the Division of Cancer Epidemiology and Genetics, part of the Intramural Program of the U.S. National Cancer Institute.

Code availability Not applicable.

\section{Declarations}

Conflicts of interest The authors have no conflicts of interest to disclose.

Open Access This article is licensed under a Creative Commons Attribution 4.0 International License, which permits use, sharing, adaptation, distribution and reproduction in any medium or format, as long as you give appropriate credit to the original author(s) and the source, provide a link to the Creative Commons licence, and indicate if changes were made. The images or other third party material in this article are included in the article's Creative Commons licence, unless indicated otherwise in a credit line to the material. If material is not included in the article's Creative Commons licence and your intended use is not permitted by statutory regulation or exceeds the permitted use, you will need to obtain permission directly from the copyright holder. To view a copy of this licence, visit http://creativecommons.org/licenses/by/4.0/.

\section{References}

1. Ma J, Jemal A (2019) Temporal trends in mortality from major cancers by education in the United States, 2001-2016. JNCI Cancer Spectrum. https://doi.org/10.1093/jncics/pkz087
2. National Center for Health Statistics: Datasets and Related Documentation for Mortality Data (2016) https://www.cdc.gov/nchs/ nvss/mortality_methods.htm. Accessed 29 Apr 2021

3. Pampel F, Legleye S, Goffette C, Piontek D, Kraus L, Khlat M (2015) Cohort changes in educational disparities in smoking: France, Germany and the United States. Soc Sci Med 127:41-50. https://doi.org/10.1016/j.socscimed.2014.06.033

4. Goding Sauer A, Siegel RL, Jemal A, Fedewa SA (2019) Current prevalence of major cancer risk factors and screening test use in the United States: disparities by education and race/ethnicity. Cancer Epidemiol Biomark Prev 28(4):629-642. https://doi.org/ 10.1158/1055-9965.Epi-18-1169

5. Winkleby MA, Schooler C, Kraemer HC, Lin J, Fortmann SP (1995) Hispanic versus white smoking patterns by sex and level of education. Am J Epidemiol 142(4):410-418

6. Blue L, Fenelon A (2011) Explaining low mortality among US immigrants relative to native-born Americans: the role of smoking. Int J Epidemiol 40(3):786-793

7. Jiang J, Feuer EJ, Li Y, Nguyen T, Yu M (2021) Inference about age-standardized rates with sampling errors in the denominators. Stat Methods Med Res 30(2):535-548

8. Rostron BL, Boies JL, Arias E (2010) Education reporting and classification on death certificates in the United States. Vital Health Stat 2(151):1-21

9. Sorlie PD, Johnson NJ (1996) Validity of education information on the death certificate. Epidemiology 7(4):437-439. https://doi. org/10.1097/00001648-199607000-00017

10. Kochanek KD MS, Xu JQ, Arias E (2019) Deaths: final data for 2017. National Vital Statistics Reports, National Center for Health Statistics, Hyattsville, MD

11. Denney JT, Rogers RG, Hummer RA, Pampel FC (2010) Education inequality in mortality: the age and gender specific mediating effects of cigarette smoking. Soc Sci Res 39(4):662-673. https:// doi.org/10.1016/j.ssresearch.2010.02.007

12. US Department of Health Human Services, Centers for Disease Control and Prevention, National Center for Chronic Disease Prevention and Health Promotion, Office on Smoking and Health (2014) The health consequences of smoking-50 years of progress: a report of the Surgeon General. Atlanta, GA

Publisher's Note Springer Nature remains neutral with regard to jurisdictional claims in published maps and institutional affiliations. 